\section{Contributors}

Gordon Baird and his father and grandfather before him have been GPs near Stranraer for over a century. His son is a medical student. Gordon has graduated from sensible cruiser-racers to faintly scary trimarans. He should be a Breton vet, aka Jean-Pierre Dick, see http://www.barcelonaworldrace.com/defa ult.asp?section=2\&sid=9313 gordon.baird@nhs.net

Ruth Bastable is not racing around the world at present. She has to cope every day with the flatness of Cambridgeshire. Rbbastable@aol.com

From Mike Fitzpatrick's womb sprang Ben Goldacre. Popper prevails! See http://www.guardian.co.uk/commentisfre e/2008/jan/05/1 All of us should prescribe rationally, grow up, think a bit, and stop seeing reps.

fitz@easynet.co.uk

Emyr Gravell is a Welsh Norman from Llanelli.

emyrwyn@doctors.org.uk

Paul Hodgkin is still (just) a GP in Sheffield. But most of the time runs www.patientopinion.org.uk - a place where Web 2.0 meets the NHS. Paul.Hodgkin@patientopinion.org.uk

Irvine Loudon was a family doctor in Oxfordshire and then retired early in his 50 s to take up an academic post in medical history. His subsequent book on the evolution of the GP and death in childbirth have been acclaimed world wide. His General Practice Under the National Health Service, 1998, is a definitive text.

irvine.loudon@wuhmo.ox.ac.uk

Adrian Sayers

sayersa@Cardiff.ac.uk

John Salinsky

JVSalinsky@aol.com

\title{
Threadbare progress
}

Apparently I don't exist any longer.

Feverishly-spinning politician's and spleen-venting newspaper columnists have been regularly proclaiming my disappearance. But l'm sure this is me, a $\mathrm{GP}$, at $3 \mathrm{AM}$, on a dark weekend morning, on his way to see an old lady who has just passed away at home. Thankfully chatting to the driver at my side helps to settle my doubts about my very existence.

Death seems to happen more at night, maybe it's just a perception but it seems to belong to the dark. The new, multivalidated, protocol-based computer triage system has advised self-care for the unfortunate departed. Now I believe in promoting patients responsibility for their own health as much as anyone, but this seems to be taking it too far. So we go and visit.

It's a gloomy ride, winding up a valley in one of the remote areas of our patch. My sense of unreality increases as I notice perfectly preserved little railway stations in several of the villages we drift through in the dark. At this time in the morning the mind can play ghostly tricks but the prosaic explanation is that steam train enthusiasts have preserved a section of old railway that would have disappeared during the Beeching reorganisation.

Confirming death is not technically difficult although I do worry about making a horrendous mistake and being the butt of incredulous newspaper headlines about people waking up in mortuaries. I take my time, my mind drifts as I listen intently to her unmoving chest. No breath or heart sounds but not silence either, and I feel like I can hear the sea just as you do with a shell to your ear. The daughter is elderly herself, composed but a little flustered, she feels more at ease when I speak Welsh.

'Would you like a cup of tea doctor ... thank you for calling ... sorry to get you out in the dark.' I haven't done much but she seems comforted by an expected part of a rite of passage.

I sometimes think that out-of-hours work, despite its frustrations and misuse, represents what I trained for. I am wrong though. It is still there, in all of general practice. When you scratch away the point chasing, box ticking and the pandering to politician's pretence that we can make people live forever if only we did our jobs better mindset something remains that has immense and immeasurable value. Plenty to improve, plenty to put right but to knock it down completely would be a disaster.

The spectral stations are reminders that progress is not always improvement, and often we only know what we've missed when it's gone. They are an eerie warning that short-term economics is not the only thing that counts and symbolise the destructive effects on communities and social cohesion that ill-thought-out progress can bring.

Private involvement, more IT, more efficient skill-mix may bring improvements, but what is lurking in the bright future of the personal, patientdriven, privately run NHS that seems so shiny and attractive on the surface? Private rail companies' safety records have been a major cause for concern and yet at high-profile train disasters the ones who had promoted the brave new corporate world were often the most vigorous shroud wavers. British Rail was a plodding bureaucratic organisation with plenty of room for improvement yet I heard the MP Gwyneth Dunwoody bemoaning the loss of the 'gossamer thread of goodwill' that existed in British Rail before privatisation.

What enrages me about current politician's ideas of modernisation is that they are just based on managerial expediency and efficiency. There is no soul or vision, and so the gossamer thread is frayed and stretched in all areas, not only the health service but also teachers, police, firemen and so on. That thread represents what is crucial to guiding change and improvement without losing what was valuable in the old.

Progress, moving forward, and improvement are an instinctive part of what drives us. It should be encouraged not suppressed, but we need to make sure that the thread isn't lost completely as we do so.

DOI: 10.3399/bjgp08X277186 